\title{
Impacts of degree of milling on the appearance and aroma characteristics of raw rice
}

\author{
Mariana Rodríguez-Arzuaga, ${ }^{a, b}$ Sungeun Cho, ${ }^{a}$ María A Billiris, ${ }^{b}$ Terry \\ Siebenmorgen ${ }^{\mathrm{a}}$ and Han-Seok Seo ${ }^{\mathrm{a}^{*}}$
}

\begin{abstract}
BACKGROUND: Little has been reported about the sensory impact of degree of milling (DOM) on raw, uncooked rice. This study focuses on the effects of DOM, which was measured by surface lipid content (SLC), on appearance and aroma attributes of raw rice, as well as the appearance of cooked rice; greater DOM leads to lesser SLC levels.

RESULTS: Milled-rice samples with SLCs of $0.64,0.59,0.42$ and $0.25 \%$, as well as brown rice $(2.27 \%$ total lipid content), were evaluated by trained panelists on three appearance- and five aroma-related attributes of raw rice, as well as four appearance-related attributes of the resultant cooked rice. All milled-rice samples, varying in SLC level from $0.64 \%$ to $0.25 \%$, differed from brown rice with respect to raw-rice and cooked-rice appearance and aroma attributes. A significant sensory difference among the four raw-rice samples was present only in the degree of whiteness; however, such a difference was absent once the samples were cooked. When cooked, highly milled rice $(0.25 \%$ SLC) was rated glossier than either lightly milled rice $(0.64 \% \mathrm{SLC})$ or brown rice.
\end{abstract}

CONCLUSION: The present study demonstrated that sensory impacts of DOM on raw rice were present between brown rice and milled-rice samples, but not among the milled-rice samples varying in SLC level from $0.64 \%$ to $0.25 \%$. The overall findings indicate that consumers may not detect appearance- or aroma-related differences among raw-rice samples ranging in SLC from $0.64 \%$ to $0.25 \%$.

(C) 2015 Society of Chemical Industry

Keywords: degree of milling; surface lipid content; appearance; aroma; raw rice; cooked rice

\section{INTRODUCTION}

Rice is typically consumed after de-hulling and milling processes. The extent to which bran is removed from rice kernels during the milling process is referred to as the degree of milling (DOM). ${ }^{1}$ With an increase of DOM, the retention of bran consequently decreases, which in turn impacts head rice yield level and the associated economic value. ${ }^{2}$ DOM has also been found to affect physicochemical and textural properties of milled rice; specifically, greater DOM generally leads to lesser levels of chemical components such as lipid, ${ }^{3,4}$ thiamin and phosphorus, ${ }^{5}$ dietary fiber, ${ }_{1}^{6}$ protein $^{6,7}$ and ash/minerals. ${ }^{6,8}$ In addition, DOM was found to positively correlate with degree of whiteness in milled rice. ${ }^{7}$ Accordingly, the levels of whiteness or surface lipid content (SLC) have been used to objectively measure the DOM of milled rice. ${ }^{4}$

Fat and hydrophobic waxy cuticles are present in the bran layers of rice, thus impeding water absorption by kernels. ${ }^{9,10}$ Therefore, as DOM increases, fat and waxy cuticle contents in the bran layers diminish, increasing the swelling ratio. ${ }^{9}$ However, DOM does not appear to relate to the duration or energy required to cook rice. Billiris et al. ${ }^{11}$ demonstrated that cooking duration and energy required for cooking were not significantly different among milled-rice samples varying in SLC level from $0.55 \%$ to $0.15 \%$. Similarly, Roy et al. ${ }^{12}$ showed no significant difference in overall energy consumption between partially and well-milled rice samples.
DOM has been shown to affect textural characteristics of cooked rice. Lyon et al. ${ }^{13}$ showed that deeply milled rice (reported as Satake whiteness meter values of 49) was rated significantly more intense in adhesiveness, stickiness to lips and starchy mouth-coating when compared to regularly milled rice (Satake whiteness meter values of 40). Similarly, Park et al. ${ }^{14}$ demonstrated that with increasing DOM adhesiveness of cooked rice increased, whereas hardness decreased; this trend was also observed by Saleh and Meullenet. ${ }^{7}$

In addition to textural characteristics, flavor attributes of cooked rice have been found to be influenced by the DOM. Champagne et al. ${ }^{15}$ demonstrated that DOM significantly affected the intensity of 'corn', 'grain-starchy', and 'water-like metallic' flavor attributes in cooked rice; however, the effect of DOM on flavor attributes was dependent on the moisture content to which rough rice had been dried, as well as the cultivar. In another study ${ }_{1}{ }^{14}$ the 'sweet taste' of cooked rice increased with an increase of DOM, while the 'puffed-corn' flavor decreased. More recently, Billiris et al. ${ }^{11}$ showed

\footnotetext{
* Correspondence to: Han-Seok Seo, Department of Food Science, University of Arkansas, 2650 North Young Avenue, Fayetteville, AR 72704, USA, E-mail:hanseok@uark.edu

a Department of Food Science, University of Arkansas, Fayetteville, AR 72704, USA

b Laboratorio Tecnológico del Uruguay, 11500 Montevideo, Uruguay
} 


\begin{tabular}{|c|c|c|}
\hline Term & Definition & Reference (anchor words) \\
\hline \multicolumn{3}{|l|}{ Appearance } \\
\hline Degree of whiteness & Degree to which sample is pure white & $\begin{array}{l}\text { Reference A: } 3.0 \\
\text { Reference B: } 10.0 \\
\text { (Yellow-White) }\end{array}$ \\
\hline Uniformity of color & Degree to which sample is one uniform color & $\begin{array}{l}\text { Reference B: } 12.0 \\
\text { (Different-All one color) }\end{array}$ \\
\hline Amount of white bellies & $\begin{array}{l}\text { Amount of white coloring found in the middle of } \\
\text { kernels }\end{array}$ & $\begin{array}{l}\text { Reference B: } 4.0 \\
\text { Reference C: } 12.0 \\
\text { (None-Much) }\end{array}$ \\
\hline \multicolumn{3}{|l|}{ Aroma } \\
\hline Dusty & Aroma associated with old books or decaying wood & $\begin{array}{l}\text { UAS } \\
\text { (None-Extremely strong) }\end{array}$ \\
\hline Grassy & Aroma associated with sweet, dry grasses or herbs & $\begin{array}{l}\text { UAS } \\
\text { (None-Extremely strong) }\end{array}$ \\
\hline Feedy & $\begin{array}{l}\text { Aroma associated with a mixture of grains, } \\
\text { reminiscent of animal feed }\end{array}$ & $\begin{array}{l}\text { UAS } \\
\text { (None-Extremely strong) }\end{array}$ \\
\hline Floral & Aroma associated with a non-specific floral note & $\begin{array}{l}\text { UAS } \\
\text { (None-Extremely strong) }\end{array}$ \\
\hline Burlap & Aroma associated with burlap rice bags & $\begin{array}{l}\text { UAS } \\
\text { (None-Extremely strong) }\end{array}$ \\
\hline
\end{tabular}

Table 2. Cooked rice appearance attributes developed in this study

\begin{tabular}{|c|c|c|}
\hline Term & Definition & $\begin{array}{c}\text { Reference }^{\mathrm{a}} \\
\text { (anchor words) }\end{array}$ \\
\hline $\begin{array}{l}\text { Degree of } \\
\text { whiteness }\end{array}$ & $\begin{array}{l}\text { Degree to which } \\
\text { sample is pure } \\
\text { white }\end{array}$ & $\begin{array}{l}\text { Reference A: } 6.0 \\
\text { Reference B: } 13.0 \\
\text { (Yellow-White) }\end{array}$ \\
\hline Glossiness & $\begin{array}{l}\text { Degree to which } \\
\text { sample is shiny }\end{array}$ & $\begin{array}{l}\text { Reference B: } 7.0 \\
\text { (Dull-Shiny) }\end{array}$ \\
\hline $\begin{array}{l}\text { Surface } \\
\text { roughness }\end{array}$ & $\begin{array}{l}\text { Degree of roughness } \\
\text { on the surface of } \\
\text { kernels }\end{array}$ & $\begin{array}{l}\text { Reference A: } 7.0 \\
\text { (Smooth-Rough) }\end{array}$ \\
\hline Visual stickiness & $\begin{array}{l}\text { Degree to which } \\
\text { kernels stick } \\
\text { together }\end{array}$ & $\begin{array}{l}\text { Reference A: } 3.0 \\
\text { Reference B: } 10.0 \\
\text { (Not sticky-Sticky) }\end{array}$ \\
\hline
\end{tabular}

${ }^{a}$ Reference A: $30 \mathrm{~g}$ Riceland Extra Long Grain Brown Rice (Riceland Foods, Stuttgart, AR); Reference B: $30 \mathrm{~g}$ Riceland Extra Long Grain Rice (Riceland Foods, Stuttgart, AR).

that specific aromas (e.g. sulfury, starchy and metallic) and flavors (e.g. sulfury) of cooked rice were perceived as significantly more intense in milled rice than in brown rice. However, the aroma and flavor attributes of cooked rice were not significantly different among rice samples that were milled to SLC levels from $0.55 \%$ to $0.15 \%$.

This study was designed to determine whether DOM, as indicated by head rice SLC, affects appearance and aroma attributes of raw rice, as well as the appearance of the resultant cooked rice, building on the recent study by Billiris et al., ${ }^{11}$ which showed the influence of DOM on aroma and flavor attributes of cooked rice. While previous studies have highlighted the effect of DOM on flavor and texture attributes of cooked rice, little attention has been paid to the sensory impact of DOM on raw rice. Paradoxically, from the standpoint of sales, raw-rice appearance and aroma attributes, in addition to non-sensory factors such as price and brand, play key roles in modulating consumers' willingness to purchase.

\section{MATERIALS AND METHODS \\ Rice samples}

Four lots of long-grain, milled-rice samples were collected from a commercial mill at Jonesboro, AR, in fall 2014. The cultivar of the rice samples was unknown. A three-break, water-mist milling system (VTA, VBF, KB-40; Satake, Hiroshima, Japan) was used to mill brown rice (2.27\% total lipid content) to four DOM levels. The SLC of head rice from each sample was subsequently measured using a Soxtec system (Avanti 2055, Foss North America Eden Praire, MN, USA) according to Matsler and Siebenmorgen; ${ }^{16}$ SLCs of the samples were $0.64 \%, 0.59 \%, 0.42 \%$ and $0.25 \%$. Each rice sample was stored in a sealed container at $4^{\circ} \mathrm{C}$. The containers were held at room temperature (approximately $20^{\circ} \mathrm{C}$ ) for $24 \mathrm{~h}$ before being used for sensory testing.

\section{Descriptive sensory analysis of raw rice}

Descriptive sensory analysis of raw rice was conducted at the University of Arkansas Sensory Service Center (Fayetteville, AR, USA). Nine professionally trained panelists, each with an average experience of greater than $1000 \mathrm{~h}$ in evaluating a variety of food products, including rice, participated in the descriptive analysis. Following a $3 \mathrm{~h}$ orientation/training session and conforming to the Spectrum method (Sensory Spectrum Inc., Chatham, NJ, USA), eight sensory attributes (three appearance- and five aroma-related attributes) were developed for descriptive analysis. Table 1 lists the definitions and reference intensities of individual sensory attributes. 

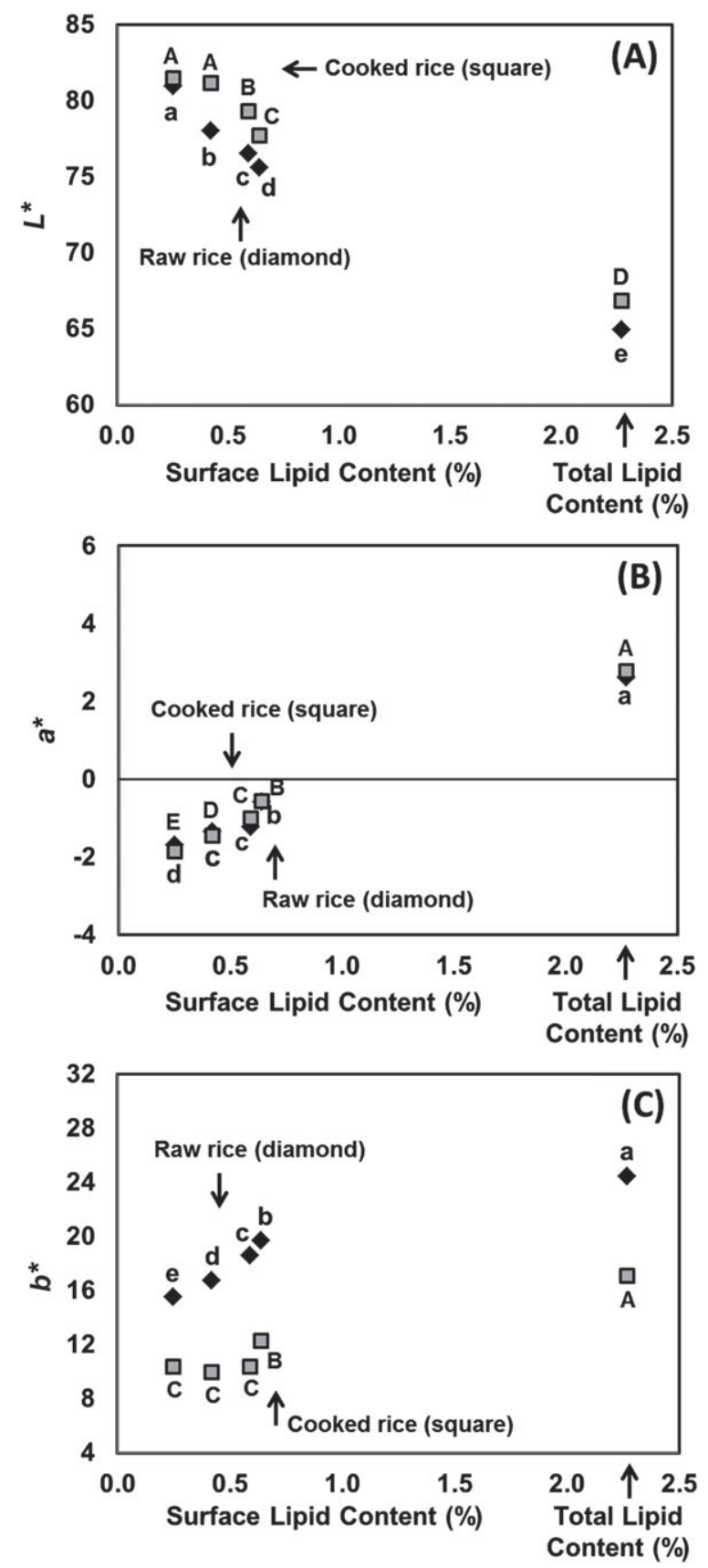

Figure 1. Color characteristics, as indicated by $\mathrm{CIE} L^{*}$ (whiteness; $\left.\mathrm{A}\right), a^{*}$ (redness; $\mathrm{B}$ ), and $b^{*}$ (yellowness; $\mathrm{C}$ ) values, of raw-rice (diamond) and cooked-rice (square) samples as a function of degree of milling (as measured by head rice surface lipid content). Brown rice had a total lipid content of $2.27 \%$, whereas milled-rice samples varied in surface lipid content from $0.64 \%$ to $0.25 \%$. Mean scores with different lower-case (or upper-case) letters represent a significant difference between raw-rice (or cooked-rice) samples $(P<0.05)$.

The trained panelists evaluated subsamples of the five raw-rice samples varying in DOM for the eight sensory attributes. Approximately $30 \mathrm{~g}$ of each rice sample was placed in a glass bowl (4 oz) covered with a glass lid. Each of the five samples was randomly presented to the panelists, one after another. Intensities of the eight sensory attributes were evaluated on 15-point numerical scales with 0.1 -increment ballots. ${ }^{17}$ Two anchor words were given to the left and right ends of each scale, as listed in Table 1. To minimize sensory fatigue, a 10 min break was allowed between sample presentations. The entire analysis was repeated, on the same day, to provide two replicate sensory evaluations of the raw-rice samples.

\section{Descriptive sensory analysis of cooked rice}

Among the nine trained panelists who participated in the descriptive analysis of raw-rice samples, seven took part in the descriptive analysis of cooked rice; two panelists were unavailable. Again, conforming to the Spectrum method, four appearance-related attributes of cooked rice were developed through a $3 \mathrm{~h}$ orientation session. Table 2 lists the definitions and reference intensities of individual appearance attributes used to characterize cooked rice.

The trained panelists evaluated subsamples of cooked rice, prepared from the same five samples used in the raw-rice evaluation above, for the four appearance-related attributes listed in Table 2. Each rice sample $(300 \mathrm{~g})$ was cooked in an electronic rice cooker (RC 101 rice cooker, Rival, Milford, MA, USA) with a 1:2 rice:water mass ratio. Immediately after cooking, a subsample from each of the five $300 \mathrm{~g}$ samples was fluffed in the rice cooker to ensure its homogeneity. Afterwards, each subsample was placed in a $4 \mathrm{oz}$ $(118 \mathrm{~mL})$ soufflé cup and covered with a plastic lid. The cooked-rice subsamples were allowed to cool by placing the covered soufflé cups in a $20^{\circ} \mathrm{C}$ sensory kitchen environment for $10 \mathrm{~min}$ prior to presenting to the panelists. ${ }^{11} \mathrm{~A}$ subsample from each of the five samples was presented at $62 \pm 2{ }^{\circ} \mathrm{C}$.

Each of the five cooked-rice subsamples was randomly presented to the panelists, one after another. Intensities of the four appearance attributes were evaluated on 15-point numerical scales with 0.1 increment ballots. ${ }^{17}$ Two anchor words were given to the left and right ends of each scale (Table 2). A 10 min break was allowed between sample presentations. The entire analysis was repeated, on the same day, to provide two replicate sensory evaluations of the cooked-rice samples.

\section{Color measurement of raw- and cooked-rice samples}

Color characteristics, as indicated by $\operatorname{CIE~} L^{*}, a^{*}$ and $b^{*}$ values, of the five raw-rice samples were measured using a colorimeter having a circular illumination opening of $3.5 \mathrm{~cm}$ diameter (Minolta CR-300, Minolta Corp., Ramsey, NJ, USA). Approximately $300 \mathrm{~g}$ of each raw-rice sample was placed in a glass dish $(14 \mathrm{~cm}$ diameter and $2 \mathrm{~cm}$ height). Color characteristics were measured at seven different surface locations of each rice sample.

Color measurements of the five cooked-rice samples were also taken using the same procedure as with the raw-rice samples, except that after placing a cooked sample in the glass dish the rice was allowed to $\mathrm{cool}$ in a $20^{\circ} \mathrm{C}$ sensory kitchen environment for $10 \mathrm{~min}$ prior to color measurement.

\section{Data analysis}

Data analyses were performed using JMP Pro (version 11.0, SAS Institute Inc., Cary, NC, USA) and XLSTAT software (Addinsoft, New York, NY, USA). To determine whether intensities of sensory attributes were significantly different due to the sample DOM, a two-way analysis of variance (ANOVA) was used, treating DOM as a fixed effect and sensory panelists as a random effect. In addition, to test whether color characteristics $\left(L^{*}, a^{*}\right.$ and $b^{*}$ values) of raw- and cooked-rice varied in relation to the DOM, one-way ANOVAs, treating DOM as a fixed effect, were used. If a significant difference in means was indicated by the ANOVA, post hoc comparisons between rice samples were performed using a Tukey HSD 


\begin{tabular}{|c|c|c|c|c|c|}
\hline \multirow[b]{2}{*}{ Sensory attributes } & \multicolumn{4}{|c|}{ Surface lipid content ${ }^{a}$} & \multirow[b]{2}{*}{ Brown rice } \\
\hline & $0.25 \%$ & $0.42 \%$ & $0.59 \%$ & $0.64 \%$ & \\
\hline \multicolumn{6}{|l|}{ Appearance } \\
\hline Degree of whiteness & $\begin{array}{l}10.9 a \\
( \pm 0.6)\end{array}$ & $\begin{array}{l}10.3 \mathrm{ab} \\
( \pm 0.7)\end{array}$ & $\begin{array}{l}9.5 \mathrm{bc} \\
( \pm 0.7)\end{array}$ & $\begin{array}{c}8.9 c \\
( \pm 1.5)\end{array}$ & $\begin{array}{c}2.9 d \\
( \pm 0.6)\end{array}$ \\
\hline Uniformity of color & $\begin{array}{l}11.6 \mathrm{a} \\
( \pm 1.0)\end{array}$ & $\begin{array}{l}11.2 \mathrm{a} \\
( \pm 1.1)\end{array}$ & $\begin{array}{l}11.2 \mathrm{a} \\
( \pm 0.9)\end{array}$ & $\begin{array}{l}10.7 \mathrm{a} \\
( \pm 0.8)\end{array}$ & $\begin{array}{c}7.7 \mathrm{~b} \\
( \pm 1.9)\end{array}$ \\
\hline Amount of white bellies & $\begin{array}{c}4.3 a \\
( \pm 1.8)\end{array}$ & $\begin{array}{c}4.5 \mathrm{a} \\
( \pm 1.3)\end{array}$ & $\begin{array}{c}5.0 \mathrm{a} \\
( \pm 0.9)\end{array}$ & $\begin{array}{c}5.0 \mathrm{a} \\
( \pm 0.7)\end{array}$ & $\begin{array}{c}5.6 \mathrm{a} \\
( \pm 2.5)\end{array}$ \\
\hline \multicolumn{6}{|l|}{ Aroma } \\
\hline Dusty & $\begin{array}{c}1.1 \mathrm{a} \\
( \pm 1.5)\end{array}$ & $\begin{array}{c}1.4 a \\
( \pm 1.6)\end{array}$ & $\begin{array}{c}1.4 \mathrm{a} \\
( \pm 1.5)\end{array}$ & $\begin{array}{c}1.5 \mathrm{a} \\
( \pm 1.6)\end{array}$ & $\begin{array}{c}1.4 a \\
( \pm 1.6)\end{array}$ \\
\hline Grassy & $\begin{array}{c}0.6 \mathrm{~b} \\
( \pm 1.2)\end{array}$ & $\begin{array}{l}1.2 \mathrm{ab} \\
( \pm 1.6)\end{array}$ & $\begin{array}{r}1.2 \mathrm{ab} \\
( \pm 1.5)\end{array}$ & $\begin{array}{r}1.5 \mathrm{ab} \\
( \pm 1.6)\end{array}$ & $\begin{array}{c}2.0 \mathrm{a} \\
( \pm 1.7)\end{array}$ \\
\hline Feedy & $\begin{array}{c}1.2 \mathrm{a} \\
( \pm 1.6)\end{array}$ & $\begin{array}{c}0.8 \mathrm{a} \\
( \pm 1.3)\end{array}$ & $\begin{array}{c}1.4 a \\
( \pm 1.6)\end{array}$ & $\begin{array}{c}1.5 \mathrm{a} \\
( \pm 1.6)\end{array}$ & $\begin{array}{c}1.4 a \\
( \pm 1.4)\end{array}$ \\
\hline Floral & $\begin{array}{c}0.9 a \\
( \pm 1.4)\end{array}$ & $\begin{array}{c}0.6 \mathrm{a} \\
( \pm 1.3)\end{array}$ & $\begin{array}{c}0.2 \mathrm{a} \\
( \pm 0.7)\end{array}$ & $\begin{array}{c}0.6 a \\
( \pm 1.4)\end{array}$ & $\begin{array}{c}0.3 a \\
( \pm 1.0)\end{array}$ \\
\hline Burlap & $\begin{array}{c}0.5 b \\
( \pm 1.1)\end{array}$ & $\begin{array}{l}1.0 \mathrm{ab} \\
( \pm 1.4)\end{array}$ & $\begin{array}{l}1.0 \mathrm{ab} \\
( \pm 1.4)\end{array}$ & $\begin{array}{l}1.0 \mathrm{ab} \\
( \pm 1.3)\end{array}$ & $\begin{array}{c}1.7 a \\
( \pm 1.4)\end{array}$ \\
\hline $\begin{array}{l}\text { Mean scores with different } \\
\text { a As measured by lipid extra } \\
\text { b Total lipid content }=2.27 \%\end{array}$ & he same & a significe & $P<0.05)$ & & \\
\hline
\end{tabular}

method. In addition, to determine a relationship between sensory attributes and DOM of raw-rice samples, a principal component analysis (PCA) was conducted. A statistically significant difference was defined as $P<0.05$.

\section{RESULTS AND DISCUSSION \\ Appearance attributes of raw rice}

As shown in Fig. 1(A), $L^{*}$ values (whiteness), as measured by a colorimeter, significantly differed among the five raw-rice samples $(F=1,059.41, P<0.001)$; $L^{*}$ values significantly increased with a decrease of SLC (i.e. with an increase of DOM). Lamberts et al. ${ }^{8}$ demonstrated that $L^{*}$ values increased until the bran and outer endosperm were removed by milling, but further milling did not affect the $L^{*}$ values. The plateau described by Lamberts et al. ${ }^{8}$ was not apparent in Fig. 1, although the least SLC (greatest DOM) was only $0.25 \%$ in the study herein. In a similar fashion to the instrumental data, sensory data (Table 3 ) showed an increasing whiteness rating of raw rice as SLC decreased ( $F=188.09$, $P<0.001)$, although there were no significant differences between the rice samples with SLC levels of $0.42 \%$ and $0.25 \%$, as well as between those with SLC levels of $0.64 \%$ and $0.59 \%$. In other words, sensory and instrumental data both indicate that the degree of whiteness of raw-rice samples increased with an increase of DOM.

Figure 1 further shows that both $a^{*}$ (redness; $F=909.28$, $P<0.001$ ) and $b^{*}$ values (yellowness; $F=318.68, P<0.001$ ), as measured by a colorimeter, decreased with a decrease in SLC (i.e. with an increase of DOM) of raw-rice samples. These trends are in line with previous studies. $8,18,19$ Red and yellow pigments are highly concentrated in the bran and endosperm periphery, whereas they are rare in the endosperm interior. 8,20 Thus the milling process would be expected to progressively remove the outer endosperm, thereby decreasing $a^{*}$ and $b^{*}$ values of raw rice. In particular, since the core endosperm contains very low levels of red pigments, ${ }^{8} a^{*}$ values of milled-rice samples with SLC levels from $0.64 \%$ to $0.25 \%$ were below 0 , as shown in Fig. $1(B)$.

As shown in Table 3, there was a numerical trend of increasing uniformity of color as DOM increased, yet there was no statistical difference in the color uniformity of raw-rice samples milled to SLC levels from $0.64 \%$ to $0.25 \%(F=22.22, P<0.001)$. This trend, in addition to the fact that the brown rice sample was rated significantly less uniform than any of the milled samples, indicates that the milling process progressively minimized unevenness of surface color. The impact of progressively milling samples to greater DOMs is also observed in the amount of white bellies seen in from brown rice compared to milled-rice with a SLC level of $0.25 \%$. There was a numerical trend in fewer white bellies as milling progressed, although this trend was not statistically significant $(P=0.10)$.

\section{Aroma attributes of raw rice}

Table 3 shows mean intensities of each of the five aroma attributes as a function of DOM of raw rice. There were significant differences in aroma intensities between brown- and highly milled rice samples. Specifically, grassy $(F=3.31, P=0.02)$ and burlap $(F=4.78$, $P=0.004)$ aroma intensities were rated significantly greater in brown rice than in highly milled rice with an SLC level of $0.25 \%$; however, there was no significant difference in grassy and burlap aroma intensities until a SLC of $0.25 \%$ was reached. This indicates that grassy and burlap aromas mainly result from the rice bran. The grassy aroma of the rice bran may result from hexanal compounds. ${ }^{21,22}$ However, brown rice did not differ from milled-rice samples with respect to the dusty, feedy and floral aroma intensities $(P>0.05)$. 


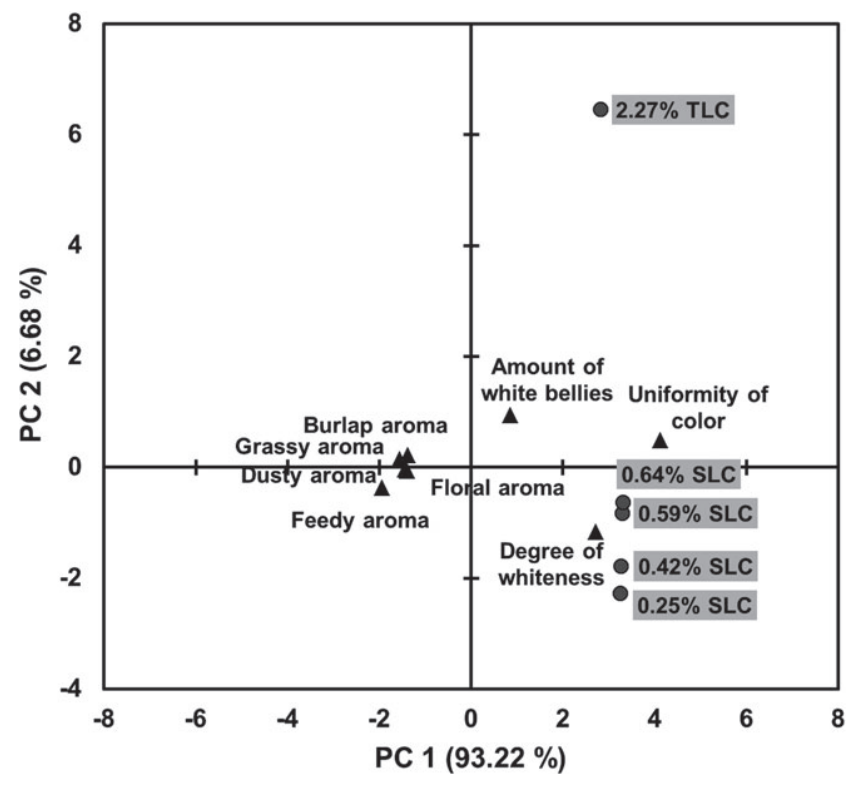

Figure 2. A principal component analysis (PCA) bi-plot for the five raw-rice samples (circles) varying in the degree of milling, as measured by head rice surface lipid content (SLC) level. Eight sensory attributes (triangles) were positioned on the bi-plot, accounting for $99.90 \%$ of the total variance, with PC1 and PC2 explaining $93.22 \%$ and $6.68 \%$, respectively. Overall, based on appearance and aroma attributes, brown rice with $2.27 \%$ total lipid content (TLC) was positioned separately from the four milled-rice samples with SLC levels from 0.64 to $0.25 \%$.

It is notable that for raw rice, none of the aroma attributes studied differed among the four milled-rice samples with SLC levels from $0.64 \%$ to $0.25 \%$ ( $P>0.05$ ). This indicates that volatile compounds related to aroma attributes are dominantly present in the rice bran (e.g. pericarp and aleurone layer). ${ }^{23}$ Consequently, removal of rice bran by progressively milling from a lightly milled ( $S L C=0.64 \%)$ to a highly milled $(S L C=0.25 \%)$ degree resulted in no statistical difference in aroma intensities among the milled-rice samples. Another plausible explanation for this lack of significant difference is that aroma intensities were rated based on a universal aromatic scale (UAS) that has been widely used for rating the aroma intensities of a variety of foods. ${ }^{17}$ More specifically, when the UAS was used, panelists were trained to consider soda aroma in saltine crackers and cooked-apple aroma in apple sauce to have intensity ratings of 3.0 and 7.0, respectively (Table 1). Since, compared to these references, milled-rice samples have much weaker aromas, their aroma intensities were scored very low (Table 3), which, in turn, may have resulted in no significant differences in aroma intensities between the milled-rice samples. Because of this point, Champagne ${ }^{24}$ argued that it is valuable to develop additional UAS references with low intensities that may help panelists evaluate aroma intensities of rice samples typically producing weak aromas.

Figure 2 shows that brown rice (2.27\% total lipid content) is separately positioned from the four milled-rice samples on a bi-plot drawn by principal component analysis (PCA) based on appearance- and aroma-related attributes of raw rice. Such a differentiation appears to result from the difference in the degree of whiteness between brown rice and milled-rice samples. The four milled-rice samples are closely positioned to each other on the PCA bi-plot, suggesting that untrained consumers may have difficulty in detecting a sensory difference among the uncooked, milled-rice samples when SLC levels ranged from
$0.64 \%$ to $0.25 \%$. Furthermore, this result indicates that the rice bran played an important role in modulating sensory aspects of raw rice.

\section{Appearance attributes of cooked rice}

Figure $1(A)$ demonstrates that cooked, milled-rice samples had significantly greater $L^{*}$ values (whiteness), as measured by a colorimeter, than brown rice $(F=679.30, P<0.001)$. In addition, $L^{*}$ values significantly differed among the four cooked-rice samples with SLC levels from $0.64 \%$ to $0.25 \%$. Specifically, $L^{*}$ values of cooked-rice samples with SLC levels from $0.42 \%$ to $0.25 \%$ were significantly greater than those with SLC levels from $0.64 \%$ to $0.59 \%(P<0.05)$. Like the instrumental data, sensory data (Table 4 ) showed that degree of whiteness was significantly greater in milled rice than in brown rice $(F=80.50, P<0.001)$. Furthermore, there was a numerical trend of increasing degree of whiteness as SLC decreased even though there were no significant differences among the four cooked, milled-rice samples.

In addition to $L^{*}$, both $a^{*}$ (redness; $F=560.16, P<0.001$ ) and $b^{*}$ values (yellowness; $F=96.57, P<0.001$ ) significantly differed among the five cooked-rice samples varying in DOM. Both $a^{*}$ and $b^{*}$ values decreased with a decrease of SLC level (Fig. 1). As opposed to raw rice, cooked rice showed no significant difference in the $b^{*}$ value among the milled-rice samples with SLC levels from 0.59 to $0.25 \%$. In addition, $b^{*}$ values of cooked rice were markedly lower than those of raw rice. This difference may be explained by the difference in moisture content between raw and cooked rice. During cooking, with an increase of DOM, water absorption by kernels increases, ${ }^{9,14}$ leading to lower pigment concentrations in cooked rice. ${ }^{8}$ As a result, DOM-induced differences in $b^{*}$ values among the raw milled-rice samples lessened in the cooked milled rice.

For the cooked-rice samples, the highly milled rice (0.25\% SLC) was rated significantly glossier than milled rice with a SLC level of $0.64 \%$, as well as brown rice $(F=9.94, P<0.001)$. However, intensities of glossiness in cooked rice did not significantly differ among the three rice samples with SLC levels from $0.59 \%$ to $0.25 \%$ $(P>0.05)$. Similarly, Park et al. ${ }^{14}$ demonstrated that the glossiness intensities in cooked rice did not significantly differ among rice samples varying in the percentage of bran removal from $14.0 \%$ to $11.0 \%$.

Cooked brown rice was visually rated less sticky than cooked milled-rice samples $(F=36.62, P<0.001)$. In a study by Park et al., ${ }^{14}$ trained panelists rated grain intactness (i.e. degree to which grains remain intact) in cooked rice significantly lower as the percentage of bran removal increased from $8.0 \%$ to $14.0 \%$. Finally, surface roughness did not significantly differ among the five cooked-rice samples $(P=0.49)$.

\section{CONCLUSION}

The present study demonstrates that DOM, as measured by head rice $S L C$, affects raw-rice appearance and aroma-related attributes, but also cooked-rice appearance. For raw rice, the impacts of DOM on appearance and aroma attributes of raw rice were most pronounced between brown rice (no milling) and milled-rice samples; while there were in most cases numerical trends, there were typically not tremendous sensory rating differences among the raw milled-rice samples varying in SLC level from $0.64 \%$ to $0.25 \%$. This indicates that untrained consumers may not detect appearanceand aroma-related differences among milled-rice samples when 
Table 4. Mean intensity scores ( \pm standard deviation) of seven professionally trained panelists' ratings of appearance attributes of cooked rice as a function of degree of milling (as indicated by surface lipid content)

\begin{tabular}{|c|c|c|c|c|c|}
\hline \multirow[b]{2}{*}{ Sensory attributes } & \multicolumn{4}{|c|}{ Surface lipid content ${ }^{a}$} & \multirow[b]{2}{*}{ Brown rice $^{b}$} \\
\hline & $0.25 \%$ & $0.42 \%$ & $0.59 \%$ & $0.64 \%$ & \\
\hline \multirow[t]{2}{*}{ Degree of whiteness } & $12.0 \mathrm{a}$ & $11.5 a$ & $11.3 a$ & $11.0 \mathrm{a}$ & $5.4 \mathrm{~b}$ \\
\hline & $( \pm 2.0)$ & $( \pm 1.5)$ & $( \pm 1.6)$ & $( \pm 1.9)$ & $( \pm 1.4)$ \\
\hline \multirow[t]{2}{*}{ Glossiness } & $7.5 a$ & $6.5 a b$ & $6.9 a b$ & $5.9 \mathrm{bc}$ & $5.3 c$ \\
\hline & $( \pm 0.8)$ & $( \pm 0.8)$ & $( \pm 0.7)$ & $( \pm 0.7)$ & $( \pm 1.3)$ \\
\hline \multirow[t]{2}{*}{ Surface roughness } & $8.3 a$ & $8.2 a$ & $8.0 \mathrm{a}$ & $8.5 a$ & $7.7 a$ \\
\hline & $( \pm 1.4)$ & $( \pm 1.1)$ & $( \pm 1.5)$ & $( \pm 1.6)$ & $( \pm 1.8)$ \\
\hline \multirow[t]{2}{*}{ Visual stickiness } & $10.2 a$ & $9.9 a$ & $9.4 a$ & $9.5 a$ & $5.7 b$ \\
\hline & $( \pm 1.0)$ & $( \pm 1.2)$ & $( \pm 1.7)$ & $( \pm 1.8)$ & $( \pm 1.9)$ \\
\hline
\end{tabular}

the SLC level ranges from $0.64 \%$ to $0.25 \%$. In a similar fashion to the raw-rice data, the effects of DOM on cooked-rice appearance were most obvious between brown rice and milled-rice samples. Since there is interest in lightly milled rice, the present findings suggest that lightly milled rice (i.e. $0.64 \%$ SLC in this study) can potentially be used to increase nutritional benefits without a noticeable difference from highly milled rice (i.e. $0.25 \% \mathrm{SLC}$ ) with respect to the appearance- and aroma-related attributes of cooked rice. As mentioned above, the authors' previous study ${ }^{11}$ found that cooking kinetics, texture and flavor of cooked rice did not significantly differ among milled-rice samples with SLC levels from $0.55 \%$ to $0.15 \%$. Based on the previous and present findings, it appears that brown rice can be lightly milled to an SLC level of $0.55 \%$ with no sensory differences in both raw- and cooked-rice samples. This conclusion is independent of potential sensory impacts of lightly milled rice at various elevated temperatures and durations.

\section{REFERENCES}

1 Chen $\mathrm{H}$ and Siebenmorgen $\mathrm{TJ}$, Effect of rice kernel thickness on degree of milling and associated optical measurements. Cereal Chem 74:821-825 (1997).

2 Sun $\mathrm{H}$ and Siebenmorgen TJ, Milling characteristics of various rough rice kernel thickness fractions. Cereal Chem 70:727-733 (1993).

3 Sibenmorgen TJ and Sun $\mathrm{H}$, Relationship between milled rice surface fat concentration and degree of milling as measured with a commercial milling meter. Cereal Chem 71:327-329 (1994).

4 Perdon AA, Siebenmorgen TJ, Mauromoustakos A, Griffin VK and Johnson ER, Degree of milling effects on rice pasting properties. Cereal Chem 78:205-209 (2001).

5 Desikachar HSR, Determination of the degree of polishing in rice. II. Determination of thiamin and phosphorus for processing control. Cereal Chem 32:78-90 (1955).

6 Fernandes Monks JL, Levien Vanier N, Casaril J, Manica Berto R, de Oliveira M, Baptista Gomes C et al., Effects of milling on proximate composition, folic acid, fatty acids and technological properties of rice. J Food Comp Anal 30:73-79 (2013).

7 Saleh MI and Meullenet J, Effect of moisture content at harvest and degree of milling (based on surface lipid content) on the texture properties of long-grain rice. Cereal Chem 84:119-124 (2007).

8 Lamberts L, De Bie E, Vandeputte GE, Veraverbecke WS, Derycke V, De Man W et al., Effect of milling on colour and nutritional properties of rice. Food Chem 100:1496-1503 (2007).
9 Desikachar HSR and Subrahmanyan V, The formation of cracks in rice during wetting and its effect on the cooking characteristics of the cereal. Cereal Chem 38:353-364 (1965).

10 Champagne ET, Wood DF, Juliano BO and Bechtel DB, The rice grain and its gross composition, in Rice Chemistry and Technology (3rd edn), ed. by Champagne ET. American Association of Cereal Chemists, St Paul, MN, 77-107 (2004).

11 Billiris MA, Siebenmorgen TJ, Meullenet J and Mauromoustakos A, Rice degree of milling effects on hydration, texture, sensory and energy characteristics. Part 1. Cooking using excess of water. J Food Eng 113:559-568 (2012).

12 Roy $\mathrm{P}$, ljiri T, Okadome $\mathrm{H}$, Nei D, Orikasa T, Nakamura N and Shiina T, Effect of processing conditions on overall energy consumption and quality of rice (Oryza sativa L.). J Food Eng 89:343-348 (2008).

13 Lyon BG, Champagne ET, Vinyard BT, Windham WR, Barton II FE, Webb $\mathrm{BD}$ et al., Effects of degree of milling, drying condition and final moisture content on sensory texture of cooked rice. Cereal Chem 76:56-62 (1999)

14 Park JK, Kim SK and Kim OK, Effect of milling ratio on sensory properties of cooked rice and on physicochemical properties of milled cooked rice. Cereal Chem 78:151-156 (2001).

15 Champagne ET, Bett KL, Vinyard BT, Webb BD, McClung AM, Barton II FE et al., Effects of drying conditions, final moisture content, and degree of milling on rice flavor. Cereal Chem 74:566-570 (1997).

16 Matsler AL and Siebenmorgen TJ, Evaluation of operating conditions for surface lipid extraction from rice using a soxtec system. Cereal Chem 82:282-286 (2005).

17 Meilgaard M, Civille GV and Carr BT, Sensory Evaluation Techniques (3rd edn). CRC Press, Boca Raton, FL (1999).

18 Lanning SB and Siebenmorgen TJ, Comparison of milling characteristics of hybrid and pureline rice cultivars. Appl Eng Agric 27:787-795 (2011).

19 Zhong Y, Liu W, Xu X, Liu C and Tu Z, Correlation analysis between color parameters and sensory characteristics of rice with different milling degrees. J Food Process Pres 38:1890-1897 (2014).

20 Lamberts $L$ and Delcour JA, Carotenoids in raw and parboiled brown and milled rice. J Agric Food Chem 56:11914-11919 (2008).

21 Krishnamurthy RG, Smouse TH, Mookherjee BD, Reddy BR and Chang SS, Identification of 2-pentylfuran in fats and oils and its relationship to the reversion flavor of soybean oil. J Food Sci 32:372-374 (1967).

22 Taylor AJ and Mottram DS, Composition and odour of volatiles from autoxidised methyl arachidonate. J Sci Food Agric 50:407-417 (1990).

23 Yang DS, Lee K-S, Lim K-J and Kays SJ, Site of origin of volatile Site of origin of volatile. Cereal Chem 85:591-598 (2008).

24 Champagne ET, Rice aroma and flavor: a literature review. Cereal Chem 85:445-454 (2008). 